\title{
ANALYSIS OF DETERMINING CRITICAL COMPONENTS USING FMECA METHOD IN SEAWATER PUMP OF DIESEL GENERATOR CATERPILLAR 3412
}

\author{
Syaiful Hasan, Erpan Sahiri, Suprayitno, Endin Tri Hartanto \\ Indonesia Naval Technology College, \\ Bumimoro-Morokrembangan Surabaya 60187, Indonesia
}

\begin{abstract}
The seawater pump on the Caterpillar 3412 Diesel Generator is one of the important component to make the Diesel generator can work well. This section serves to circulate seawater for the heat transfer process. The seawater pump is part of a cooling system of the engine which keeps the engine temperature from being too overheat. Seawater pumps with continuous operational conditions, resulting in reduced component reliability. This study applies the FMECA method to identify opportunities for failure at the seawater pump. From the calculation of FMECA, it is obtained an assessment of the level of risk from a failure model that can give priority scale to preventive maintenance that can be done in the future. FMECA analysis of 27 components in seawater pump on the Diesel Generator, found 7 components that had RPN values above the average. The following are the 4 components with the highest RPN value, namely Shaft (7C-3493) RPN value 420,44; Key (175-6716) $R P N$ value 300,31; Bearing Inner (4M-6107) RPN value 285 and Bearing Roller (3N-8463) RPN value 253,13. Components that have high RPN values require more attention, such as routine checks and periodic maintenance.
\end{abstract}

Keyword: Seawater pump, Caterpillar 3412 Diesel Generator, FMECA, RPN.

\section{INTRODUCTION.}

The engine temperature greatly affects the performance of the engine. If the engine temperature is too cold, the brake power released will be smaller because it has to increase the engine temperature at a working temperature first. Conversely, if the engine temperature is too hot it will reduce the performance and brake power (Choudhary, Tiwari, Vardhan, \& Kaushal, 2014). To maintain the temperature of the diesel engine not overheat needed a cooling system. In the cooling system have a part in the circulating seawater is a seawater pump. The seawater is circulated to the heat exchanger to cooling the freshwater. The freshwater is tasked with cooling all components of the engine.

Continuous operation of the diesel generator will reduce the value of reliability components, so we need to make a preventive maintenance schedule. Especially the seawater pump which has the most frequent amount of damage compared to other system units. It is necessary to identify what components can cause failure and what are the consequences of the failure. This must be done to maintain the readiness of the diesel generator.

Previous literature used as references include Jun \& Huibin (2012) researching about Reliability Analysis of Aircraft Equipment Based on FMECA Method. Hasbullah \& Ahmad (2015) researching about Failure Analysis of Tyre Production Process Using FMECA Method. Deng (2015) researching about A Research on Subway Physical Vulnerability Based on Network Theory and FMECA. Renjith, kalathil, Kumar, \& Madhavan
(2018) researching about Fuzzy FMECA (failure mode effect and criticality analysis) of LNG Storage Facility.

This research uses the FMECA method to identify the causes of failures and their effects on the system, then the risks are assessed using Severity, Occurrence and Detection assessments so that the most critical parts are identified. The part that has the highest Risk Priority Number (RPN) value is categorized as the riskiest component. Those components must be given priority for repairs.

\section{MATERIAL AND METHODS.}

\subsection{Seawater Pump.}

The type of seawater pump under study is a seawater pump driven by engine speed. The pump type is a centrifugal pump. Centrifugal pump as a particular case of turbomachinery. A typical centrifugal pump (Figure 1) consists of an impeller, which has some channels delimited by curved blades, that rotates inside a spiral shape casing (the volute). Rotation of the impeller forces the fluid (usually liquid) to circulate through the pump from the axial to the radial direction while energy is transferred to the fluid (Karassik, Messina, Cooper, \& Heald, 2001). During this continuous process non-steady fluid-dynamic forces are produced, both at single frequencies and with broad-band spectra. The former is usually associated with the frequency of rotation, the passing-blade frequency, and their harmonics. Excitation at the frequency of rotation may be provoked by impeller whirling, when the impeller has an orbital motion coupled to the 
rotation, and, also, by small manufacturing imperfections in the impeller. Excitation at the passing-blade frequency (frequency of rotation multiplied by the number of blades of the impeller) is a consequence of the finite thickness of the blades, which causes flow disturbances in the volute associated with the passage of each blade. The effects of those excitation mechanisms may be substantially modified by impeller-stator interaction phenomena, which are dependent on the point of operation of the pump (Parrondo, Fernandez, Santolaria, \& Gonzalez, 1996).

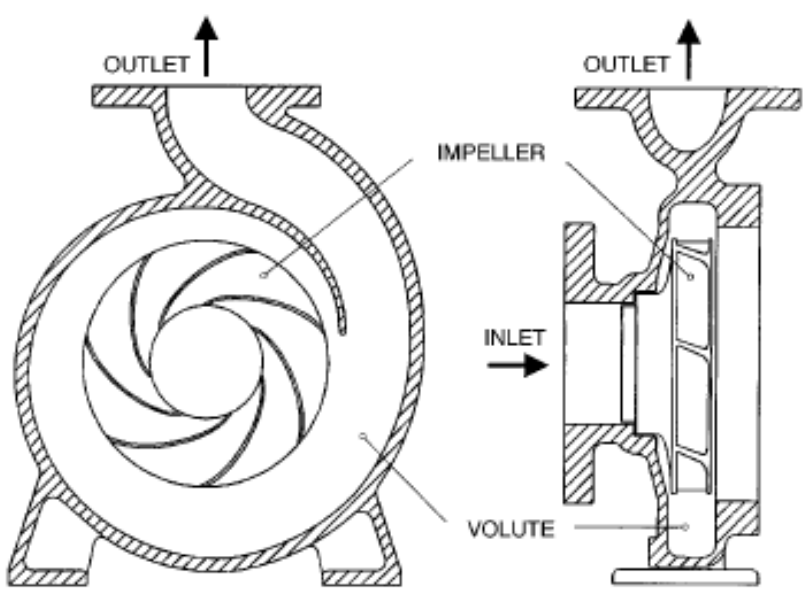

Fig. 1 Centrifugal Pump.

(Parrondo, Velarde, \& Santolaria, 1998)

\subsection{FMECA}

The FMECA was originally developed by the National Aeronautics and Space Administration (NASA) to improve and verify the reliability of space program hardware. MIL-STD-785, entitled Reliability Program for System and Equipment Development and Production. Failure Mode, Effects and Criticality Analysis call out the procedures for performing a FMECA on equipment or systems. MIL-STD-1629 is the military standard that establishes requirements and procedures for performing a FMECA, to evaluate and document, by failure mode analysis, the potential impact of each functional or hardware failure on mission success, personnel and system safety, maintainability and system performance. Each potential failure is ranked by the severity of its effect so that corrective actions may be taken to eliminate or control design risk. High risk items are those items whose failure would jeopardize the mission or endanger personnel. The techniques presented in this standard may be applied to any electronic or mechanical equipment or system. MIL-STD-1629 is applicable during the development phases of all DoD systems and equipment as well as commercial and industrial products (Borgovini, Pemberton, \& Rossi, 1993).

Risk Priority Number (RPN) is the result of multiplication weights of Severity (S), Occurrence (O) and Detection (D). These results will be able to determine the critical components of the system.

$$
\mathrm{RPN}=(\mathrm{S}) \times(\mathrm{O}) \times(\mathrm{D})
$$

The Risk Priority Number is used to rank and identify the concerns or risks associated with the operation due to the design. This number will provide a means to prioritize which components should be evaluated by the team to reduce their calculated risk through some type of corrective action or maintenance efforts. However, when severity is at a high level, immediate corrective action may be given regardless of the resultant RPN (ARMY, 2006).

Table 1. FMECA's Severity, Occurrence, and Detection.

\begin{tabular}{llll}
\hline Severity & Occurrence & Detection & Score \\
\hline Dangerously High & $\lambda>0.01$ & Absolute Uncertainty & 10 \\
Extremely High & $0.01>\lambda>5^{*} 10^{-3}$ & Very Remote & 9 \\
Very High & $5^{*} 10^{-3}>\lambda>2.5^{*} 10^{-3}$ & Remote & 8 \\
High & $2.5^{*} 10^{-3}>\lambda>10^{-3}$ & Very Low & 7 \\
Moderate & $10^{-3}>\lambda>5^{*} 10^{-4}$ & Low & 6 \\
Low & $5^{*} 10^{-4}>\lambda>10^{-4}$ & Moderate & 5 \\
Very Low & $10^{-4}>\lambda>5^{*} 10^{-5}$ & Moderately High & 4 \\
Minor & $5^{*} 10^{-5}>\lambda>10^{-6}$ & High & 3 \\
Very Minor & $10^{-6}>\lambda>10^{-7}$ & Very High & 2 \\
None & $10^{-7}>\lambda$ & Almost Certain & 1 \\
\hline
\end{tabular}

Table 2. Consequence/severity Level. 


\begin{tabular}{|c|c|c|c|}
\hline Severity Level & $\begin{array}{c}\text { Descriptions } \\
\text { for Severity } \\
\text { Level }\end{array}$ & Definition for Severity Level & $\begin{array}{c}\text { Applicable to Functional } \\
\text { Groups for }\end{array}$ \\
\hline 1 & $\begin{array}{l}\text { Minor, } \\
\text { Negligible, }\end{array}$ & $\begin{array}{c}\text { Function is not affected, no } \\
\text { significant operational delays. } \\
\text { Nuisance. }\end{array}$ & \multirow{5}{*}{$\begin{array}{c}\text { Propulsion } \\
\text { Directional Control } \\
\text { Drilling } \\
\text { Position Mooring (Station Keeping) } \\
\text { Hydrocarbon Production and } \\
\text { Processing } \\
\text { Import and Export Functions }\end{array}$} \\
\hline 2 & $\begin{array}{l}\text { Major, } \\
\text { Marginal, } \\
\text { Moderate }\end{array}$ & $\begin{array}{l}\text { Function is not affected, however } \\
\text { failure detection/corrective } \\
\text { measures not functional. OR } \\
\text { Function is reduced resulting in } \\
\text { operational delays. }\end{array}$ & \\
\hline & Critical, & Function is reduced, or damaged & \\
\hline 3 & $\begin{array}{l}\text { Hazardous, } \\
\text { Significant }\end{array}$ & $\begin{array}{l}\text { machinery, significant operational } \\
\text { delays }\end{array}$ & \\
\hline 4 & $\begin{array}{c}\text { Catastrophic, } \\
\text { Critical }\end{array}$ & Complete loss of function & \\
\hline
\end{tabular}

(American Bureau of Shipping, 2016)

Table 3. Probability of Failure.

\begin{tabular}{|c|c|}
\hline Likelihood Descriptor $^{(j)}$ & Description \\
\hline Improbable & Fewer than 0.001 events year \\
\hline Remote & 0.001 to 0.01 events/year \\
\hline Occasional & 0.01 to 0.1 events/year \\
\hline Probable & 0.1 to 1 events/year \\
\hline Frequent & 1 or more events/year \\
\hline
\end{tabular}

(American Bureau of Shipping, 2016)

Table 4. Risk Matrix.

\begin{tabular}{|c|c|c|c|c|c|}
\hline \multirow{2}{*}{ Sworin Land } & \multicolumn{5}{|c|}{ 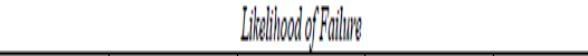 } \\
\hline & Inpowhable & Renole & Omosiona & Rowolle & Arymati \\
\hline A & Netrom & High & Hidy & Higl & High \\
\hline 3 & Low & Nerion & Hey & High & $\mathrm{High}$ \\
\hline l & Lorr & Loil & Vediou & $\mathrm{High}$ & High \\
\hline 1 & Low & Lorl & Loll & Netion & Netion \\
\hline
\end{tabular}

(American Bureau of Shipping, 2016)

\subsection{Research Methodology}

To solve problems in the observed research, steps are needed and determined to describe the approach and model of the problem. The steps taken are:

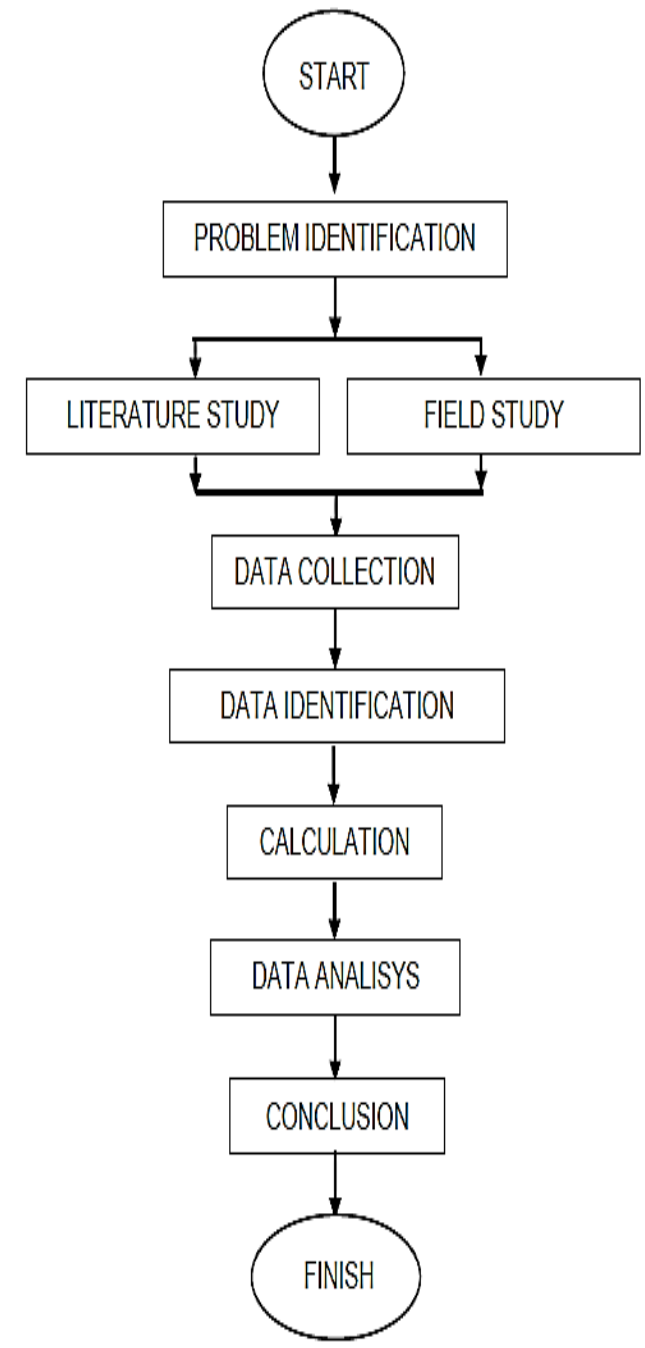

Fig. 2 Research Methodology.

3. RESULT AND DISCUSSION.

This is the arrangement components of seawater Pump on the Caterpillar 3412 Diesel Generator 


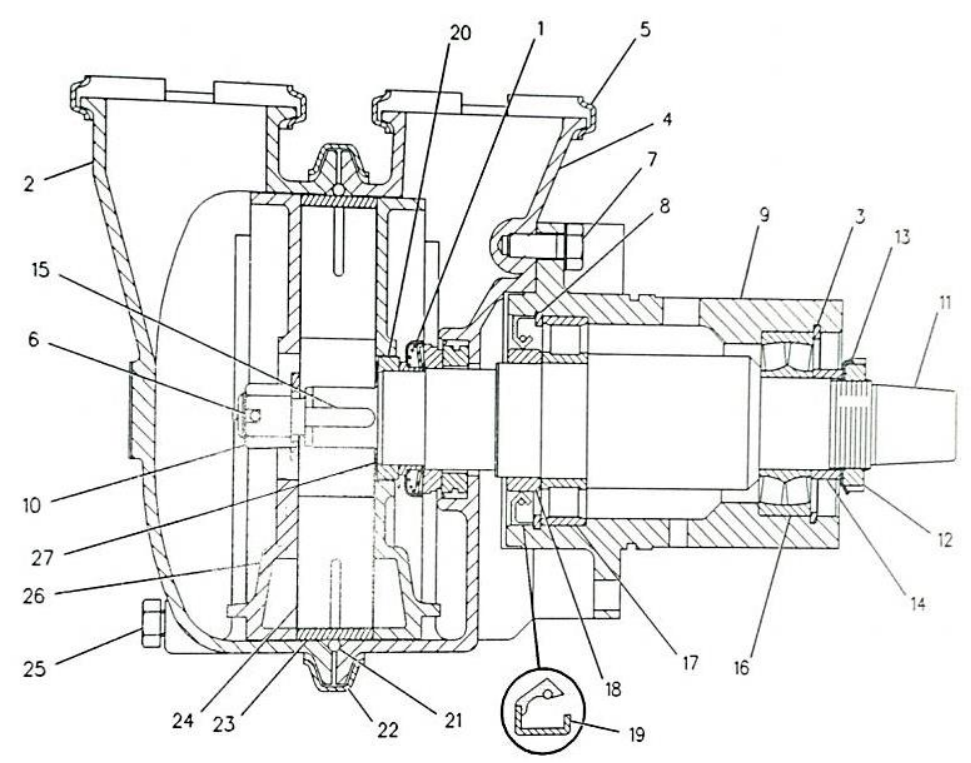

Fig. 3 Sea Water Pump. (Caterpillar, 2004)

Data identification of potential component failures that affect the operation of Sea Water Pump is obtained below:

Table 5. Identification of Potential Failure.

\begin{tabular}{|c|c|c|c|c|c|}
\hline NO & ITEM & $\begin{array}{l}\text { PART } \\
\text { NUMBER }\end{array}$ & $\begin{array}{l}\text { POTENTIAL } \\
\text { FAILURE }\end{array}$ & DAMAGE & CODE \\
\hline 1 & Seal GP Water & $5 \mathrm{~N}-6055$ & Broken & The pump is leak out & C1 \\
\hline 2 & Body Drive End & $3 \mathrm{~N}-8448$ & Corrosion & The pump is leak out & $\mathrm{C} 2$ \\
\hline 3 & Clip & $107-5565$ & Broken & Bearing is not running well & C3 \\
\hline 4 & Body Drive End & $3 N-8447$ & Corrosion & The pump is leak out & $\mathrm{C} 4$ \\
\hline 5 & Clamp As & $3 \mathrm{~N}-8468$ & Broken & Leak on the connection & C5 \\
\hline 6 & Pin Cotter & 4P-9312 & Broken & The nut is not closed maximal & C6 \\
\hline 7 & Bolt High Temperature & $107-4910$ & $\begin{array}{l}\text { Broken, } \\
\text { Worn Out }\end{array}$ & $\begin{array}{l}\text { the shaft will vibrate cause not } \\
\text { center }\end{array}$ & C7 \\
\hline 8 & Ring Retaining & $1 \mathrm{~J}-6472$ & Worn Out & Position of Bearing is not correct & $\mathrm{C} 8$ \\
\hline 9 & Housing Bearing & $61-2092$ & Worn Out & Position of Bearing is not correct & C9 \\
\hline 10 & Nut Slotted & $7 X-2652$ & Worn Out & The impeller will be vibrate & $\mathrm{C} 10$ \\
\hline 11 & Shaft & $7 C-3493$ & $\begin{array}{l}\text { Broken, } \\
\text { Worn Out }\end{array}$ & Impeller Pump can not spin & C11 \\
\hline 12 & Nut Bearing & $8 B-7614$ & Worn Out & Position of Bearing is not correct & C12 \\
\hline 13 & Lock Nut & 8B-7613 & Worn Out & The nut is not closed maximal & $\mathrm{C} 13$ \\
\hline 14 & Spacer & $3 N-8445$ & Worn Out & Position of Bearing is not correct & $\mathrm{C} 14$ \\
\hline 15 & Key & $175-6716$ & $\begin{array}{l}\text { Broken, } \\
\text { Worn Out }\end{array}$ & The impeller will be vibrate & C15 \\
\hline 16 & Bearing Roller & $3 N-8463$ & Jammed & The pump can not spin & C16 \\
\hline 17 & Bearing Inner & $4 \mathrm{M}-6107$ & Jammed & The pump can not spin & C17 \\
\hline 18 & Collar Seal & $5 \mathrm{~N}-2904$ & Worn Out & An oil leak occurred & C18 \\
\hline 19 & Seal Oil & $5 \mathrm{~N}-2902$ & Worn Out & An oil leak occurred & C19 \\
\hline 20 & Washer & $3 \mathrm{~N}-8442$ & Worn Out & The shaft is not running well & $\mathrm{C} 20$ \\
\hline 21 & Seal O Ring & $3 N-8462$ & $\begin{array}{l}\text { Break, } \\
\text { Worn Out }\end{array}$ & Leak on the connection & $\mathrm{C} 21$ \\
\hline 22 & Clamp As & $3 N-8469$ & Broken & Leak on the connection & $\mathrm{C} 22$ \\
\hline 23 & Ring & $3 N-8452$ & Worn Out & The impeller is not running well & $\mathrm{C} 23$ \\
\hline 24 & Impeller & $3 N-8$ & $\begin{array}{l}\text { Broken, } \\
\text { Corrosion }\end{array}$ & $\begin{array}{l}\text { The pump can not spin, Pressure } \\
\text { of water will be reduced }\end{array}$ & $\mathrm{C} 24$ \\
\hline 25 & Plug & $104-1718$ & Worn Out & A water leak occurred & $\mathrm{C} 25$ \\
\hline
\end{tabular}




\begin{tabular}{|c|l|c|l|l|c|}
\hline NO & \multicolumn{1}{|c|}{ ITEM } & $\begin{array}{c}\text { PART } \\
\text { NUMBER }\end{array}$ & $\begin{array}{c}\text { POTENTIAL } \\
\text { FAILURE }\end{array}$ & \multicolumn{1}{|c|}{ DAMAGE } & CODE \\
\hline 26 & Plate Port & $5 \mathrm{~N}-4504$ & Worn Out & $\begin{array}{l}\text { The pressure of water will be } \\
\text { reduced }\end{array}$ & C26 \\
\hline 27 & Shim & $3 \mathrm{~N}-8441$ & Worn Out & Possition of Impeller is not correct & C27 \\
\hline
\end{tabular}

After the above steps, the values of Severity $(\mathrm{S})$, Occurrence $(\mathrm{O})$, and Detection (D) are determined from each component. Weight of the causes of failure based on the assessment of four experts. Then calculated to find out the size of the Risk Priority Number.

Table 6. Data Calculation.

\begin{tabular}{|c|c|c|c|c|c|c|c|c|c|c|c|c|c|}
\hline ODE & & \multicolumn{4}{|c|}{0} & & RPN \\
\hline C1 & 7 & 6 & 8 & 7 & 5 & 5 & 6 & 4 & 4 & 5 & 4 & 4 & 148,75 \\
\hline $\mathrm{C} 2$ & 2 & 3 & 2 & 2 & 1 & 2 & 2 & & & 1 & 1 & 1 & 3,94 \\
\hline $\mathrm{C3}$ & & 4 & 3 & 5 & & 3 & 3 & 3 & & 7 & 7 & 6 & 91 \\
\hline C4 & & 2 & 2 & 3 & 1 & 2 & 2 & 2 & & 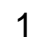 & 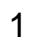 & & \\
\hline $\mathrm{C5}$ & & 2 & 2 & 2 & 2 & 3 & 2 & 0 & 2 & 2 & 1 & 2 & 8,75 \\
\hline $\mathrm{C} 6$ & & 3 & 3 & 4 & 2 & 3 & 4 & 3 & 8 & 8 & 8 & 8 & 78 \\
\hline C7 & 2 & 2 & 3 & 3 & 1 & 1 & 2 & 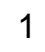 & 3 & 2 & 2 & 2 & 7,03 \\
\hline C8 & & 4 & 5 & 4 & 3 & 4 & 4 & 4 & 8 & 7 & 7 & 7 & \\
\hline C9 & & 5 & 5 & 5 & 5 & 4 & 5 & 5 & 5 & 5 & 4 & 5 & 112,81 \\
\hline $\mathrm{C} 10$ & 5 & 5 & 5 & 5 & 2 & 3 & 2 & 3 & 7 & 7 & 6 & 7 & 84,38 \\
\hline C11 & 8 & 8 & 8 & 7 & 8 & 8 & 7 & 8 & 7 & 6 & 7 & 8 & 420,44 \\
\hline $\mathrm{C} 12$ & & 5 & 6 & 6 & & 6 & 5 & 4 & & 4 & 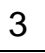 & 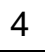 & 7 \\
\hline C13 & 5 & 5 & 6 & 5 & 3 & 3 & 4 & 3 & 4 & 3 & 3 & 4 & 59,72 \\
\hline C14 & 4 & 5 & 5 & 5 & 2 & 3 & 3 & 2 & 7 & 6 & 7 & 6 & 77,19 \\
\hline C15 & $t$ & 8 & 8 & 8 & 7 & 8 & 8 & 8 & 5 & 5 & 5 & 5 & 300,31 \\
\hline C16 & 7 & 8 & 8 & 7 & 7 & 8 & 8 & 7 & 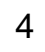 & 4 & 5 & 5 & 253,13 \\
\hline C17 & 8 & 8 & 8 & 8 & 7 & 7 & 8 & 8 & 4 & 5 & 5 & 5 & 285 \\
\hline C18 & 6 & 6 & 7 & 5 & 5 & 4 & 4 & 3 & 5 & 5 & 5 & 4 & 114 \\
\hline C19 & 7 & 6 & 8 & 7 & 8 & 8 & 8 & 8 & 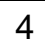 & 4 & 4 & 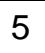 & 238 \\
\hline $\mathrm{C} 20$ & 6 & 6 & 5 & 6 & 4 & 4 & 5 & 4 & 5 & 5 & 4 & 5 & 116,08 \\
\hline $\mathrm{C} 21$ & 5 & 5 & 4 & 6 & 4 & 6 & 5 & 6 & 3 & 3 & 2 & 2 & 5,63 \\
\hline C22 & 2 & 2 & 3 & 2 & 2 & 3 & 3 & 3 & 2 & 2 & 2 & 1 & 10,83 \\
\hline C23 & $\checkmark$ & 5 & 6 & 6 & 3 & 3 & 3 & 2 & 3 & 7 & 6 & 6 & 102,09 \\
\hline C24 & 7 & 8 & 8 & 8 & 6 & 7 & 6 & 6 & 3 & 3 & 5 & 4 & 181,64 \\
\hline C25 & 2 & 2 & 3 & 2 & 2 & 3 & 4 & 3 & 1 & 1 & 1 & 1 & 6,75 \\
\hline $\mathrm{C} 26$ & 4 & 4 & 3 & 5 & 4 & 4 & 3 & 5 & 7 & 7 & 6 & 5 & 100 \\
\hline C27 & & 0 & 4 & 4 & $\checkmark$ & 1 & 3 & 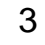 & & $r$ & 0 & 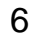 & 85,31 \\
\hline
\end{tabular}




\section{Failure Mode Chart}

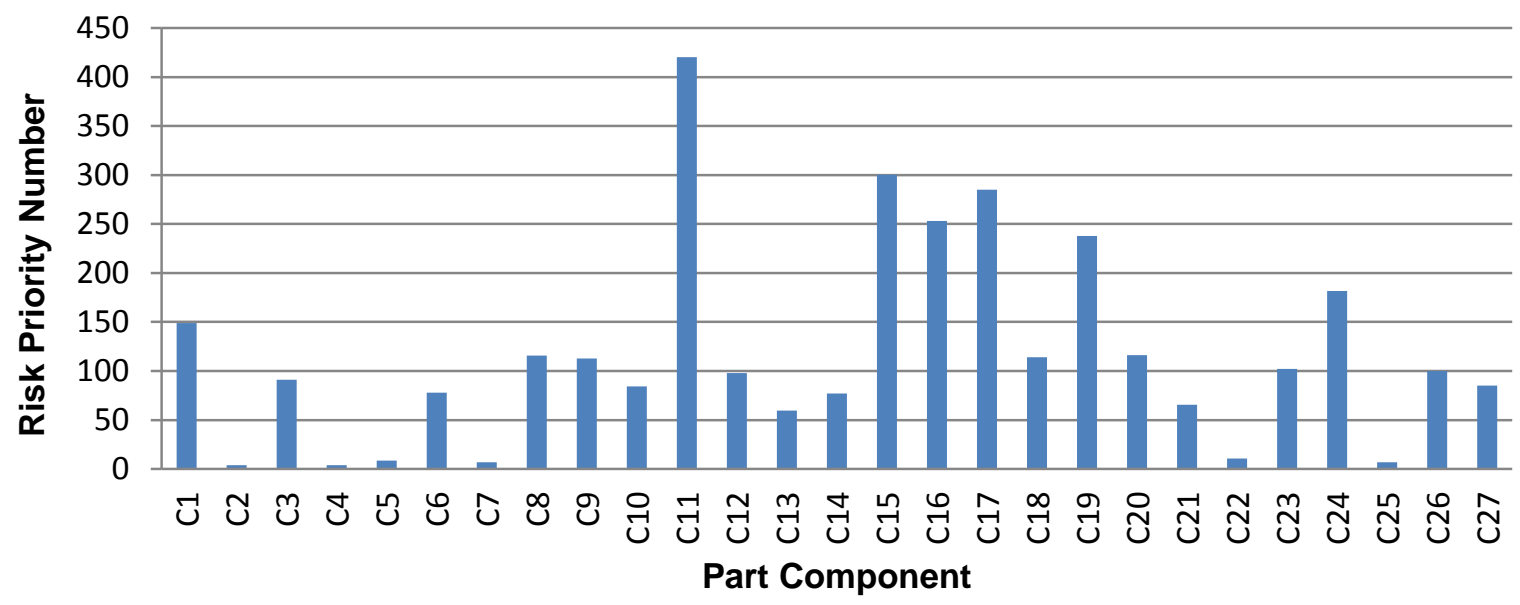

Fig. 4 Failure Mode Chart.

Table 7. Risk Matrix.

\begin{tabular}{|c|c|c|c|c|}
\hline No & CODE & $\begin{array}{c}\text { Consequence I } \\
\text { severity Level }\end{array}$ & $\begin{array}{c}\text { Probability of } \\
\text { Failure }\end{array}$ & Risk Rating \\
\hline 1 & C11 & 3 & Probable & High \\
\hline 2 & C15 & 3 & Probable & High \\
\hline 3 & C17 & 3 & Probable & High \\
\hline 4 & C16 & 3 & Probable & High \\
\hline 5 & C19 & 3 & Probable & High \\
\hline 6 & C24 & 3 & Occasional & High \\
\hline 7 & C1 & 3 & Occasional & High \\
\hline 8 & C20 & 3 & Remote & Medium \\
\hline 9 & C8 & 2 & Remote & Low \\
\hline 10 & C18 & 3 & Remote & Medium \\
\hline 11 & C9 & 2 & Occasional & Medium \\
\hline 12 & C23 & 2 & Remote & Low \\
\hline 13 & C26 & 2 & Remote & Low \\
\hline 14 & C12 & 3 & Occasional & High \\
\hline 15 & C3 & 2 & Remote & Low \\
\hline 16 & C27 & 2 & Remote & Low \\
\hline 17 & C10 & 2 & Remote & Low \\
\hline 18 & C6 & 2 & Remote & Low \\
\hline 19 & C14 & 2 & Remote & Low \\
\hline 20 & C21 & 2 & Occasional & Medium \\
\hline 21 & C13 & 2 & Remote & Low \\
\hline 22 & C22 & 1 & Remote & Low \\
\hline 23 & C5 & 1 & Row \\
\hline 24 & C7 & 2 & Low \\
\hline 25 & C25 & 1 & Low \\
\hline 26 & C2 & 1 & Low \\
\hline 27 & C4 & 1 & Low \\
\hline
\end{tabular}




\section{CONCLUSION.}

The results of the analysis of 27 components on the Caterpillar 3412 Sea Water Pump Diesel Generator, obtained 7 components that have RPN values above the average and have Risk Rating High categorize. The following are the 4 components with the highest RPN value, namely Shaft (7C-3493) RPN value 420.44; Key (175-6716) RPN value of 300.31 ; Bearing Inner (4M-6107) RPN 285 value and Bearing Roller (3N-8463) RPN value 253.13. Components that have high RPN values require more attention, such as routine checks and periodic maintenance, so that the lifetime of the machine will increase and always be ready to operate.

\section{REFERENCES}

ABS. (2016). Surveys Based on Machinery Reliability and Maintenance Techniques. New York: American Bureau of Shipping.

ARMY, D. O. (2006). Failure Modes, Effect and Criticality Analysis (FMECA) for Command, Control, Communication, Computer, Intelligence, Surveillance, and Reconnaissance (C4ISR) Facilities. Washington D.C.

Borgovini, R., Pemberton, S., \& Rossi, M. (1993). Failure Mode, Effects and Criticality Analysis (FMECA). New York: Reliability Analysis Center.

Caterpillar. (2004). Parts manual 3412 C Marine Auxiliary Generator Set.

Choudhary, S., Tiwari, A., Vardhan, A., \& Kaushal, A. (2014). The Effect of Engine Temperature on Multi Cylinder SI Engine Performance with Gasoline as a fuel. International Journal of Engineering Research and General Science, 2(5), 497-505.
Deng, Y. (2015). A Research on Subway Physical Vulnerability Based on Network Theory and FMECA. Journal of Safety Science, 127-134.

Hasbullah, N. H., \& Ahmad, R. (2015). Failure Analysis of Tyre Production Process Using FMECA Method. Case Studies in Engineering Failure Analysis.

Jun, L., \& Huibin, X. (2012). Reliability Analysis of Aircraft Equipment Based on FMECA Method. Physics Procedia, 25, 1816 - 1822.

Karassik, I. J., Messina, J. P., Cooper, P., \& Heald, C. C. (2001). Pump Handbook (3rd ed.). New York: McGraw-Hill.

Melani, A. H., Murad, C. A., Netto, A. C., Souza, G. F., \& Nabeta, S. I. (2018). Criticality-based Maintenance of a Coal-fired Power Plant. Energy, 147, 767-781.

Parrondo, J. L., Velarde, S., \& Santolaria, C. (1998). Development of a Predictive Maintenance System For a Centrifugal Pump. Journal of Quality in Maintenance Engineering, 3, 198-211.

Parrondo, J., Fernandez, J., Santolaria, C., \& Gonzalez, J. (1996). Measurements in The Dynamic Pressure Field of The Volute of a Centrifugal Pump. Hydraulic Machinery and Cavitation, 401-410.

V.R. Renjith, M. J. (2018, January). Fuzzy FMECA (failure mode effect and criticality analysis) of LNG Storage Facility. Journal of Loss Prevention in the Process Industries. 